\title{
On the Practice of Cultivating Non-English Major's Intercultural Awareness through Oscar Best Pictures
}

\author{
Huijian Wang, Huijun Fu, Pan Chen \\ College of Foreign Language Education and International Business, Baoding University, Baoding, China \\ Email: lanyu2003flower@163.com
}

How to cite this paper: Wang, H. J., Fu, H. J., \& Chen, P. (2021). On the Practice of Cultivating Non-English Major's Intercultural Awareness through Oscar Best Pictures. Creative Education, 12, 2410-2423.

https://doi.org/10.4236/ce.2021.1210181

Received: September 26, 2021

Accepted: October 25, 2021

Published: October 28, 2021

Copyright (c) 2021 by author(s) and Scientific Research Publishing Inc. This work is licensed under the Creative Commons Attribution International License (CC BY 4.0).

http://creativecommons.org/licenses/by/4.0/

\begin{abstract}
Based on the requirement of College English Teaching Guide and discussion about researches on movie teaching, this project carried out empirical research to illustrate the practical effect of appreciating Oscar best Pictures on non-English majors' cultural learning and cultivating their intercultural awareness in the process of college English teaching. It is hoped that this exploration will serve as a stimulus for further study to arouse college English teachers' and non-English majors' thinking and attention to English culture learning and intercultural awareness.
\end{abstract}

\section{Keywords}

Non-English Majors, Intercultural Awareness, Oscar Best Pictures

\section{Introduction}

The Teaching Guidance Committee (2020) points out: one of the teaching objectives of College English is to cultivate students' application ability, enhance inter-cultural awareness and competence, getting students capable of using English appropriately and effectively in study, life and future work. This indicates it is very important to consider imparting cultural knowledge in English teaching. In intercultural communication, language learners and users must know about the cultural system of the target language and learn about how the native speakers of the target language look at things, how they observe the world, and how they use the language to reflect their thoughts and behavior, so the learners and users can select the appropriate language and expression according to different cultural background, to achieve the purposes of effective communication. Therefore, language teaching is not only the teaching of the language itself; it should also in- 
clude culture teaching.

For Chinese college students, due to the influence of learning environment, living environment, ideological concepts and other aspects, few college students can independently seek opportunities to participate in foreign cultural exchanges. They have a low degree of attention to inter-cultural exchange activities and lack of interest. At the same time, they lack of systematic learning which results in insufficient knowledge reserve of foreign cultural knowledge as a support. The acquisition and storage of inter-cultural knowledge requires college students to accumulate bit by bit from daily learning. They should be able to familiarize themselves with the other party's national culture, national history and have a certain language foundation. But for most non-English majors, it is difficult for them to get enough knowledge support in the text books used in classroom.

Since feature movies are beneficial to mobilizing students' enthusiasm of learning, to students' thinking and understanding of English, to helping students to experience real communicative language and improve skills of communication, and to helping students to enhance awareness of cross-cultural learning. This practice aims to explore the practical effectiveness of appreciating Oscar best Pictures on non-English majors' cultural learning and cultivating their intercultural awareness in the process of college English teaching.

\section{Literature Review}

The first educational film came into being in 1910. At the beginning of the 1920 's, the visual education is produced. And then, the audio-visual education came into being in 1940's and developed faster in 1960's. In 1965, the Stanford University adopted Computer Assisted Instruction. Application of films in college teaching had been accepted in 1970's.

Some scholars stressed the use of movie clips when teaching languages. For example, Blakely (1984) thought that there was a good learning effect if students had a complete understanding of language and cultural background revealed in the movie before they watch it. Carr \& Duncan (1987) opposed to appreciate movies aimlessly, they thought it would be much better to watch a clip with purpose and it would be much more effective than watching the whole movie for hours. Natush (1990) advocated using movie clips to teach language features.

Some other scholars proposed the use of the complete movies on language teaching. Voller \& Widdows (1993) considered that movies were texts. From this angle, movies are the carrier of information. Besides, Ishihara \& Chi (2004) strongly emphasized using a full-length movie to practice listening and speaking.

In China, Zhu Xiaomei (2010) explored the promotion of English movies on college English teaching from students' English application capacity and intercultural communication capacity and offers suggestions to use English movies efficiently. Zhang $\mathrm{Lu}$ (2009) explored the effect of the Anglo-American movies on teaching cultural information and improving cultural awareness. Zhao Fuxia (2005) summarized the features and benefits of film for teaching, such as a mov- 
ie (or clip) can be used as a case to provide cultural experience, from the multi-party and performance at all levels of the culture, and demonstrate the feasibility and necessity for cultural teaching. Liu Xiaofeng (2008) discussed that it was good in situational teaching to choose excellent English movies as teaching contents which combine listening and speaking. In her former study, the author and coworkers, Wang, H.J., Huang, Y. and Dong, L. (2021), talked about advantages of Oscar Best Pictures in Intercultural Awareness Cultivation. With their unique aesthetic value and cultural identity, Oscar Best Pictures are more effective than textbooks, literature and other written and listening materials used in cultivating college students' intercultural awareness.

\section{Methodology}

\subsection{Subjects}

140 non-English major undergraduates were selected to be the participants of this research. They are from 3 different majors of Baoding University. They have learnt English for almost 6 to 10 years, aged from $17-20$. The author gives them college English lectures. They have taken part in kinds of exams, including the National Entrance Examination. They have a certain basis of English language, culture and literature knowledge, and certain intercultural awareness. And they would further their English study and take it as a compulsory course. It is of help and effect to make them carry on the experiment.

\subsection{Instruments}

The research instruments employed in this research include a socio-cultural test for pretest, one questionnaire for both pre-test and post-test and statistical software SPSS 18.0.

\subsubsection{Instrument 1: A Socio-Cultural Test-Pre-Test}

A socio-cultural test was applied as a pre-test to gain a clear view about the socio-cultural competence of the three classes. This test is mainly based on "A Socio-cultural Test" of Wang Zhenya and designed by the author in part.

It consists of three sections. The first section is about nonverbal interactions, covering body language, attitudes towards time and space, social customs, norms, relationship, etc. The second section aims to test verbal communicative competence of the subjects, including greeting, addressing, offering invitations, making proposal, expressing gratitude, etc. The third section is about cultural knowledge.

\subsubsection{Instrument 2: A Questionnaire for both Pre-Test and Post-Test}

The questionnaire with 20 statements was used to investigate students' current situation and changes of intercultural awareness before and after the teaching practice. It might cover attitudes to different culture, understanding of different culture, the sensitivity of cultural difference, and how to deal with cultural difference. It is mainly adapted from Chen and Starost's Intercultural Sensitivity 
Scale and adjusted by the author in part for the convenience of calculation.

\subsection{The Procedure}

\subsubsection{Giving Pre-Test}

At the beginning of the semester, the author organized a socio-cultural test and a questionnaire as the pre-test in three classes to get a perceptual view of current situation of non-English majors' cultural knowledge and intercultural awareness. The authors distributed the test papers and questionnaire and explained the instructions clearly. They were asked to finish the test within 30 minutes and 20 minutes. During the process no discussion was permitted. If they finished, they handed in quietly without interrupting the others. At last, all test papers were collected. Then the authors evaluated and analyzed the collected data cautiously.

\subsubsection{IA Cultivation for the Experimental Class}

In the second semester of 2020 to 2021 academic year, the experiment program was processed and finished over a 14-week period (from March 8, 2021 to June 11, 2021). Class 1 of 40 students was from Ideological and Political Education treated as the Experimental Class (EC). Class 2 of 40 students was from Preschool Education treated as the Control Class (CC). Before the experiment went, all the students in EC had been notified that the program would include a certain number of western culture information and need their cooperation which involved their endeavor both inside and outside of the classroom.

The textbook applied in the two classes is New Vision College English, published by Foreign Language Teaching and Research Press. During the teaching process, besides the text book, Oscar Best Pictures were adopted in the EC to offer cultural information and cultivate their intercultural awareness. While for the CC, the students were taught cultural information with the help of text book only.

In the process, students were required to discuss about the related cultural knowledge such as: history, geography, customs, policy, religion, and so on. Students should appreciate Oscar Best Pictures as much as possible before or after class according to the researcher's arrangement.

The author selected four pieces of films according to time sequence, including Gone with the Wind (1939), My Fair Lady (1964) Forrest Gump (1994) and No Country for Old Man (2007).

Taking Gone with the Wind for example:

Step 1: The teacher recommends the movie on Super Star learning APP;

Step 2: The teacher introduces the outline of the film on the APP, especially the main characters such as the hero and heroine;

Step 3: Then the teacher assigns tasks for the students to finish after class. First, they should watch the film on the Internet. Then, they should also answer the following questions:

1) When did the story take place? (history)

2) Where did the story take place? (geography) 
3) What do you know about the Christian family? (religion)

4) Compare it with Chinese culture of the same time and find out the cultural differences.

Note: They have to finish the task in the form of a poster with group members.

Step 4: Students share their learning achievements in class group by group in four weeks. And each time, there are 15 minutes for them to express their opinion or their feeling after appreciating the film.

Step 5: The teacher gives students some minutes to make a summary, and let them see the film again after class to deepen their impression on the former discussions.

\subsubsection{Giving Post-Test}

Thirteen weeks later the same survey as a post-test was conducted in both classes under the supervision of the author in the 14th week (June 11, 2021). After the papers were collected, the data were examined and analyzed by the researchers.

\section{Results and Discussion}

\subsection{The Result and Discussion of Pre-Test}

\subsubsection{The Result and Discussion of Socio-Cultural Test}

In the test of cultural knowledge, the maximum is 70 , the minimum is 25 , the mean is 45.0714 and the standard deviation is 8.67034 . From the data above, we can know that students of these three classes are at a low level of intercultural knowledge (Table 1, Table 2).

In the test of nonverbal communication, the maximum is 65 , the minimum is 25 , the mean is 44.5357 , and the standard deviation is 8.91399 . In the test of verbal communication, the maximum is 70 , the minimum is 25 , the mean is 46.6071 and the standard deviation is 8.91399. From the data above, students of these three classes are at a low level of intercultural communication overall. In contrast, they did a better job in verbal communication than non-verbal communication.

\subsubsection{The Result and Discussion of Questionnaire Survey \\ 1) Reliability}

Reliability analysis is a major tool to test the reliability and stability of the instrument of measurement. To make sure the stability and reliability of the questionnaire, the author selected internal consistency reliability coefficient as indicator of evaluation questionnaires.

In exploratory research, it is usually required that Cronbach a coefficient should be 0.6 at least in scale, Cronbach a coefficient should be 0.7 or higher, that the consistency reliability would be better, if it is 0.8 or higher, the consistency reliability is considered very well. From Table 3, it's known that the Cronbach a coefficient of the questionnaire is 0.651 and the standardized value is 0.705 , showing that the questionnaire has a better reliability. 
Table 1. Descriptive statistics of cultural knowledge.

\begin{tabular}{lccccc}
\hline & N & Minimum & Maximum & Mean & Std. Deviation \\
\hline Cultural knowledge & 140 & 25.00 & 70.00 & 45.0714 & 8.67034 \\
Valid N (list wise) & 140 & & & & \\
\hline
\end{tabular}

Table 2. Descriptive statistics of Non-verbal and verbal communication.

\begin{tabular}{cccccc}
\hline & N & Minimum & Maximum & Mean & Std. Deviation \\
\hline Non-verbal communication & 140 & 25.00 & 65.00 & 44.5357 & 8.91399 \\
Verbal communication & 140 & 25.00 & 70.00 & 46.6071 & 8.40238 \\
Valid N (list wise) & 140 & & & & \\
\hline
\end{tabular}

Table 3. Reliability statistics.

\begin{tabular}{ccc}
\hline Cronbach's Alpha & Cronbach's Alpha Based on Standardized Items & N of Items \\
\hline 0.651 & 0.705 & 20 \\
\hline
\end{tabular}

\section{2) Normality Analysis}

After inputting all the data collected, it should be done first to analyze classes' normality test. The authors used single sample K-S test of non-parametric test to see whether the scores of these three classes are in normal distribution. Judging from the results, the statistic value of $\mathrm{Z}$ in $\mathrm{K}$-S was separately $1.340,1.254$ and 1.337 , and $P=0.55,0.86$ and 0.56 , the level is significantly greater than 0.5 . So the null hypothesis was accepted that there was no significant difference between the distribution of test scores and theoretical normal distribution, that is to say, the scores of each class were in normal distribution at the level of 0.05 , which are shown in Tables 4-6.

\section{3) Difference analysis}

The scores in each class are normally distributed; while it can be tested whether there is significant difference between each class by Independent-samples Test. There were Independent-samples Tests between class 1 and class 2, class 1 and class 3, class 2 and class 3 to compare the means of each class. After comparison and contrast, the author chose class 1 as the experimental class and class 2 as control class, because this group was closer than another two groups in the item of means. The data are shown in Table 7.

The means of class 1 and class 2 were 65.3250 and 65.4500, the standard deviation of them were 3.39975 and 3.46373 respectively, and they were equal variance, $p=0.871$, which is significantly greater than the level of 0.05 . Therefore, the null hypothesis should be accepted that there was no significant difference in the overall distribution of two independent samples, namely there is no statistically significant difference between class 1 and class 2 on inter-cultural awareness.

In addition, according to the investigation, the subjects of three classes share some common features. Firstly, the period for their exposure to English is iden- 
tical. Furthermore, they are all native Chinese who were born and brought up in mainland China. Thus, they share similarly cultural and social background. And none of them have even been to a western country.

Table 4. One-Sample kolmogorov-smirnov test of Class 1 Pre-test.

\begin{tabular}{ccc}
\hline & & Total score \\
\cline { 3 - 3 } $\mathrm{N}$ & & 40 \\
\hline Normal Parameters & Mean & 65.3250 \\
Valid N (list wise) & Std. Deviation & 3.39975 \\
& Absolute & 0.212 \\
Kolmogorov-Smirnov Z & Positive & 0.140 \\
Asymp. Sig. (2-tailed) & Negative & -0.212 \\
\hline
\end{tabular}

a. Test distribution is Normal. b. Calculated from data.

Table 5. One-Sample kolmogorov-smirnov test of Class 2 Pre-test.

\begin{tabular}{ccc}
\hline $\mathrm{N}$ & & Total score \\
\cline { 3 - 3 } & & 40 \\
\hline Normal Parameters & a,b & 65.4500 \\
Valid N (list wise) & Std. Deviation & 3.46373 \\
& Absolute & 0.198 \\
& Positive & 0.128 \\
Kolmogorov-Smirnov Z & Negative & -0.198 \\
Asymp. Sig. (2-tailed) & & 1.254 \\
\hline
\end{tabular}

a. Test distribution is Normal. b. Calculated from data.

Table 6. One-Sample kolmogorov-smirnov test of Class 3 Pre-test.

\begin{tabular}{|c|c|c|c|}
\hline \multirow{2}{*}{$\mathrm{N}$} & & & \multirow{2}{*}{$\begin{array}{c}\text { Total score } \\
40\end{array}$} \\
\hline & & & \\
\hline Normal Parameters & $\mathrm{a}, \mathrm{b}$ & Mean & 65.7500 \\
\hline \multirow[t]{4}{*}{ Valid N (list wise) } & & Std. Deviation & 3.50605 \\
\hline & & Absolute & 0.173 \\
\hline & & Positive & 0.144 \\
\hline & & Negative & -0.173 \\
\hline Kolmogorov-Smirnov Z & & & 1.337 \\
\hline Asymp. Sig. (2-tailed) & & & 0.056 \\
\hline
\end{tabular}

a. Test distribution is Normal. b. Calculated from data. 
Table 7. Independent samples test of Class 1 and Class 2 pre-test.

\begin{tabular}{|c|c|c|c|c|c|c|c|c|c|c|}
\hline & & Class & & $\mathrm{N}$ & \multicolumn{2}{|c|}{ Mean } & \multicolumn{2}{|c|}{ Std. Deviation } & \multicolumn{2}{|c|}{ Std. Error Mean } \\
\hline \multirow{2}{*}{\multicolumn{2}{|c|}{ Total score }} & Class 1 & & 40 & \multicolumn{2}{|c|}{65.3250} & \multicolumn{2}{|l|}{3.39975} & \multicolumn{2}{|c|}{0.53755} \\
\hline & & Class 2 & & 40 & \multicolumn{2}{|c|}{65.4500} & \multicolumn{2}{|c|}{3.46373} & \multicolumn{2}{|c|}{0.54766} \\
\hline & & \multicolumn{3}{|c|}{$\begin{array}{l}\text { Levene's Test for } \\
\text { Equal of Variance }\end{array}$} & \multicolumn{4}{|c|}{ t-test for Equality of Means } & & \\
\hline & & \multirow[t]{2}{*}{$\mathrm{F}$} & Sig. & \multirow[t]{2}{*}{$\mathrm{t}$} & \multirow[t]{2}{*}{$\mathrm{df}$} & \multirow[t]{2}{*}{ Sig. (2 tailed) } & \multirow[t]{2}{*}{ Mean difference } & \multirow[t]{2}{*}{$\begin{array}{l}\text { Std. Error } \\
\text { Difference }\end{array}$} & $\begin{array}{r}\text { Confider } \\
\text { of the I }\end{array}$ & $\begin{array}{l}\text { interval } \\
\text { ference }\end{array}$ \\
\hline & & & & & & & & & Upper & Lower \\
\hline \multirow{2}{*}{$\begin{array}{l}\text { Total } \\
\text { score }\end{array}$} & $\begin{array}{c}\text { Equal variance } \\
\text { assured }\end{array}$ & 0.007 & 0.935 & -0.163 & 78 & 0.871 & -.1250 & 0.76739 & -1.66276 & 1.40276 \\
\hline & $\begin{array}{c}\text { Equal variance not } \\
\text { assured }\end{array}$ & & & -0.163 & 77.973 & 0.871 & -.1250 & 0.76739 & -1.66277 & 1.40277 \\
\hline
\end{tabular}

\subsection{Results and Discussion of Post-Test}

\subsubsection{Normality Analysis}

The authors used single sample K-S test of non-parametric test to see whether the scores of these two classes are in normal distribution. Judging from the results, the statistic value of $\mathrm{Z}$ in $\mathrm{K}-\mathrm{S}$ was separately 1.120 and 0.755 , and $P=0.163$ and 0.619 , the level is significantly greater than 0.5 . So the null hypothesis was accepted that there was no significant difference between the distribution of test scores and theoretical normal distribution, that is to say, the scores of the two classes were in normal distribution at the level of 0.05 , which are shown in Table 8 and Table 9.

\subsubsection{Difference Analysis}

The scores in each class are normally distributed, so it can be tested whether there is significant difference between pre-test and post-test with Paired samples Test. There was Independent-samples Test between pre and post-test of class 1 and class 2, Independent-samples Tests between post-test of class 1 and class 2 to compare the means of each class and find out whether there is significant change between them, shown in Tables 10-12.

1) The means of class 1 pre-test is 65.3250 and that of class 1 post-test is 71.1000 , the standard deviation of pre-test is 3.39975 and that of post-test is 4.25351, and they are correlated with each other. In Paired Sample Test, $p=$ 0.000 , which is significantly lower than the level of 0.05 . Therefore, the null hypothesis should not be accepted that there was no significant difference in the overall distribution of two independent samples, namely there is statistically significant difference between pre-test and post-test of class 1 in intercultural awareness.

2) The means of class 2 pre-test is 65.4500 and that of class 1 post-test is 68.6500 , the standard deviation of pre-test is 3.46373 and that of post-test is 3.57735 , and they are correlated with each other. In Paired Sample Test, $p=$ 
0.000 , which is significantly lower than the level of 0.05 . Therefore, the null hypothesis should not be accepted that there was no significant difference in the overall distribution of two independent samples, namely there is statistically significant difference between pre-test and post-test of class 2 in intercultural awareness, shown in Tables 13-15.

Table 8. One-Sample kolmogorov-smirnov test of Class 1 Post-test.

\begin{tabular}{ccc}
\hline & & Total score \\
Normal Parameters & Mean & 40 \\
\hline Most Extreme & Std. Deviation & 71.1000 \\
Differences & Absolute & 4.25351 \\
Kolmogorov-Smirnov Z & Positive & 0.177 \\
Asymp. Sig. (2-tailed) & Negative & 0.177 \\
\hline
\end{tabular}

a. Test distribution is Normal. b. Calculated from data.

Table 9. One-Sample kolmogorov-smirnov test of Class 2 Post-test.

\begin{tabular}{|c|c|c|c|}
\hline \multirow{2}{*}{$\mathrm{N}$} & & & Total score \\
\hline & & & 40 \\
\hline \multirow[t]{2}{*}{ Normal Parameters } & $\mathrm{a}, \mathrm{b}$ & Mean & 68.6500 \\
\hline & & Std. Deviation & 3.57735 \\
\hline Most Extreme & & Absolute & 0.179 \\
\hline \multirow[t]{2}{*}{ Differences } & & Positive & 0.097 \\
\hline & & Negative & -0.119 \\
\hline Kolmogorov-Smirnov Z & & & 0.755 \\
\hline Asymp. Sig. (2-tailed) & & & 0.619 \\
\hline
\end{tabular}

a. Test distribution is Normal. b. Calculated from data.

Table 10. Paired samples statistics of Class 1.

\begin{tabular}{cccccc}
\hline & Mean & N & Std. Deviation & Std. Error Mean \\
\hline \multirow{2}{*}{ Pair 1 } & Pre-test & 65.3250 & 40 & 3.39975 & 0.53755 \\
& Post-test & 71.1000 & 40 & 4.25351 & 0.67254 \\
\hline
\end{tabular}

Table 11. Paired sample correlations of Class 1.

\begin{tabular}{ccccc}
\hline & & N & Correlation & Sig. \\
\hline Pair 1 & c & 40 & 0.531 & 0.000 \\
\hline
\end{tabular}


Table 12. Paired sample test of Class 1.

\begin{tabular}{|c|c|c|c|c|c|c|c|c|c|}
\hline & & \multicolumn{5}{|c|}{ Paired Differences } & & & \\
\hline & & & & & $\begin{array}{r}95 \% \\
\text { Interval }\end{array}$ & $\begin{array}{l}\text { idence } \\
\text { Difference }\end{array}$ & & & \\
\hline & & Mean & Std. Deviation & Std. Error Mean & Lower & Upper & $\mathrm{t}$ & $\mathrm{df}$ & Sig. (2 tailed) \\
\hline Pair 1 & Pre-test \& Post-test & -5.77500 & 3.77908 & .59752 & -6.98361 & -4.56639 & -9.665 & 39 & 0.000 \\
\hline
\end{tabular}

Table 13. Paired samples statistics of Class 2.

\begin{tabular}{cccccc}
\hline & & Mean & N & Std. Deviation & Std. Error Mean \\
\hline \multirow{2}{*}{ Pair 1 } & Pre-test & 65.4500 & 40 & 3.46373 & 0.54766 \\
& Post-test & 68.6500 & 40 & 3.57735 & 0.56563 \\
\hline
\end{tabular}

Table 14. Paired sample correlations of Class 2.

\begin{tabular}{ccccc}
\hline & & N & Correlation & Sig. \\
\hline Pair 1 & $c$ & 40 & 0.855 & 0.000 \\
\hline
\end{tabular}

Table 15. Paired sample test of Class 2.

\begin{tabular}{lccccccccc}
\hline & \multicolumn{9}{c}{ Paired Differences } \\
\cline { 2 - 9 } & \multicolumn{9}{c}{$\begin{array}{c}95 \% \text { Confidence Interval } \\
\text { of the Difference }\end{array}$} \\
\cline { 2 - 9 } & Mean & Std. Deviation & Std. Error Mean & Lower & Upper & t & df & Sig. (2 tailed) \\
\hline Pair 1 Pre-test \& Post-test & -3.20000 & 1.89737 & 0.30000 & -3.80681 & -2.59319 & -10.667 & 39 & 0.000 \\
\hline
\end{tabular}

From the data analysis above, it can be inferred that the non-English majors' intercultural awareness was improved in both EC and CC. But whether there is difference between post-tests of the two classes, the author used Independent Samples Test to verify.

The means of class 1 and class 2 were 71.1000 and 68.6500, the standard deviation of them was 4.25351 and 3.57735 respectively, and they were equal variance, $p=0.007$, which is significantly lower than the level of 0.05 . Therefore, the null hypothesis should not be accepted that there was no significant difference in the overall distribution of two independent samples, namely there is statistically significant difference between class 1 and class 2 in intercultural awareness after the teaching practice, shown in the Table 16 and Table 17.

It can be drawn that, the appreciation of Oscar Best Pictures plays a greater role than text book only in cultivating non-English majors' intercultural awareness, which helps to achieve the purpose of this study. For most students, they can appreciate various life and value, which not only improves their language proficiency but also gives them a sense of beauty when appreciating and contrasting foreign cultures and Chinese cultures.

The data also show that, however, some subjects remain a low intercultural awareness after appreciating Oscar Films. They don't care about it at all. This may be caused by their individual situation, or personal interest. 
Table 16. Group statistics of paired sample test of Class 1 and Class 2.

\begin{tabular}{cccccc}
\hline & Class & $\mathrm{N}$ & Mean & Std. Deviation & Std. Error Mean \\
\hline \multirow{2}{*}{ Total score } & Class 1 & 40 & 71.1000 & 4.25351 & 0.67254 \\
& Class 2 & 40 & 68.6500 & 3.57735 & 0.56563 \\
\hline
\end{tabular}

Table 17. Table independent sample test of paired sample test of Class 1 and Class 2.

\begin{tabular}{|c|c|c|c|c|c|c|c|c|c|}
\hline & \multicolumn{2}{|c|}{$\begin{array}{l}\text { Levene's Test for } \\
\text { Equal of Variance }\end{array}$} & \multicolumn{7}{|c|}{ t-test for Equality of Means } \\
\hline & \multirow[t]{2}{*}{$\mathrm{F}$} & \multirow[t]{2}{*}{ Sig. } & \multirow[t]{2}{*}{$\mathrm{t}$} & \multirow[t]{2}{*}{ df } & \multirow[t]{2}{*}{ Sig. (2 tailed) } & \multirow[t]{2}{*}{$\begin{array}{c}\text { Mean } \\
\text { difference }\end{array}$} & \multirow[t]{2}{*}{$\begin{array}{l}\text { Std. Error } \\
\text { Difference }\end{array}$} & \multicolumn{2}{|c|}{$\begin{array}{l}\text { Confidence interval } \\
\text { of the Difference }\end{array}$} \\
\hline & & & & & & & & Upper & Lower \\
\hline Total Equal variance assured & 1.3217 & 0.254 & 2.788 & 78 & 0.007 & 2.45000 & 0.87877 & 0.70050 & 4.19950 \\
\hline score Equal variance not assured & & & 2.788 & 75.774 & 0.007 & 2.45000 & 0.87877 & 0.69969 & 4.20031 \\
\hline
\end{tabular}

\section{Implications of IA Cultivation through Oscar Best Pictures}

Teacher plays a critical instructive role in class. To a large extent, college students always perform under the guidance of their teachers. So teachers should be aware of it and set a correct direction and give a wise guidance for their film appreciation.

\subsection{Selection and Interpretation of Films}

As the organizer, teachers should select film with care. The selected Oscar Best films should be representative, which involve the main social and cultural aspects of the English-speaking countries, covering political system, economic system, education system, social security system and other aspects of marriage and the family; including religion, national identity, cultural areas, values, mass media and Folklore shows, etc., and it will be better to choose masterpiece with distinctive character of era, or with artistic value and appreciable value which can arouse thinking and worth to be pondered.

Teachers need to list the difficult points appear to help students have a better understanding of the plot and dialogue, help them to understand the deep meaning and profound cultural meaning of the words. Teachers can divide the film into several fragments and assign tasks accordingly. For the incomprehensible plots and discourse, teachers should ask students to repeat viewing until they can understand.

\subsection{Teacher's Appropriate Guidance}

Teachers should consciously guide and organize learners to participate in a variety of interactive activities, create an environment to enhance their awareness of activity participation and to motivate students' all-round development.

Guiding them to learn cultural background. Before the appreciation, teachers should prompt students the aspects which are to be noted, introduce the main content, special plots and main characters, and consciously guide the students to 
know about the historical background, cultural background and other information, instead of giving them comprehensive and detailed presentation of background information. Teachers can design some appropriate questions according to the films and let them finish it with the purpose of understanding them.

Guiding them to analyze the cultural differences. For the diversity of cultural difference, teachers should guide students to analyze the cultural difference between different countries in class, rather than tell them directly, this kind of exploratory learning is helpful for students to compare similarities and contrast differences on the East and West initiatively which is good for gradually developing students' sensitivity to cultural differences and cultivating students' intercultural awareness.

Guiding them to appreciate after class. Teachers can offer a recommendation on the arrangement of appreciating films, and students can adjust the plan according to their personal situation and even make their own plans, but the point is to finish the task on time. In addition, the after-school tasks should be appropriate, it should not be burden to students; otherwise, it would be counterproductive.

Guiding them to discuss or write feedback. When finishing each part of the film, ask students to discuss in or between groups, to share their opinions on a certain phenomenon; when finishing the whole film, ask students to write feedback, such as their feelings. In this way, students can deeply understand and analyze the subject revealed in the film; analyze character's personality traits or an event combining with the historical background of the film and express their own opinions, enhancing the understanding of the English countries' culture.

\subsection{Students' Autonomous Learning at Extracurricular Time}

After class, students should carry out extensive activities in the form of group work, such as speech, film dubbing, role play and group drama. In this way, cultural learning and intercultural awareness cultivation can be extended to extra-curricular. As a result, it will inspire students' enthusiasm and sense of participation.

In addition, it is very useful for students to repeat some clips. Students can repeat and imitate some moderate dialogue, which can help strengthen the theme of the film, strengthen students' understanding of the contents and strengthen students' feeling about the experience character, all of which can allow students more deeply understand the language and culture.

\section{Conclusion}

Based on a discussion about researches on movie teaching, the teaching practice was conducted to verify whether Oscar Best Pictures appreciation has a positive effect on non-English majors' intercultural awareness. The results of the experiment indicated that Oscar Best Pictures appreciation can improve students' intercultural awareness effectively which verified the aim of this study. The reason 
is that Oscar Best Pictures appreciating improves learners' intercultural awareness by reinforcing students' culture knowledge in a moving and live context, as well as by improving their intercultural competence on account of their active activities of appreciating, discussion, comparing and feedback. The author hopes that the above findings could be instructive for future English teaching, learning and research, especially for cultivating non-English majors' intercultural awareness. It is also expected that the strategies employed in the experiment can provide college English teachers with some suggestions to carry out activities when appreciating Oscar Best Pictures to improve students' inter-cultural awareness.

However, on account of various constraints, the present study has certain limitations in terms of sampling, methodology and generalizability. One of them is that it is confined to only one college and only two natural classes with 80 students. Therefore, the findings cannot be fully generalized to all college and university students in a province or throughout the country. Another limitation is that although the practice had been conducted for a semester and some positive results had been achieved, the issue itself remains a topic of discussion. After all, there is a complex relationship between Oscar Best Picture appreciating and the cultivation of intercultural awareness and it is worthy of a longitudinal study.

\section{Conflicts of Interest}

The authors declare no conflicts of interest regarding the publication of this paper.

\section{References}

Blakely, R. (1984). Teaching Film with Blinders on: The Importance of Knowing the Language. ADFL Bulletin, 16, 42-47. https://doi.org/10.1632/adfl.16.1.42

Carr, T., \& Duncan, J. (1987). The VCR Revolution: Feature Films for Language and Cultural Proficiency in Birckbichcer (pp. 64-68). National Textbook Co.

Ishihara, N., \& Chi, J. C. (2004). Authentic Video in the Beginning ESOL Classroom: Using a Full-Length Feature Film for Listening and Speaking Strategy Practice. English Teaching Forum-Online, 42, 1.

Liu, X. F. (2008). An Empirical Study on Using Video to Promote ICC in the Foreign Language Classroom. Guangdong University of Foreign Studies.

Natush, B. (1990). Capturing Life-like Language from Films in Video Vignettes. The Language Teacher, 14, 19-21.

Teaching Guidance Committee (2020). The College English Teaching Guide (pp. 8-17). Higher Education Press.

Voller, P., \& Widdows, S. (1993). Feature Films as Text: A framework for Classroom Use. ELT Journal, 47, 342-353. https://doi.org/10.1093/elt/47.4.342

Wang, H. J., Huang, Y., \& Dong, L. (2021). Cultivation of Non-English Majors Intercultural Awareness via Appreciating Oscar Best Pictures. Creative Education, 12, 1655-1665. https://doi.org/10.4236/ce.2021.127126

Zhang, L. (2009). Effects of English Films on Chinese Students' Culture Learning. Shanghai International Studies University.

Zhao, F. X. (2005). Using Film as Means to Develop International Competence for Chi- 
na's EFL Students. Shanghai International Studies University.

Zhu, X. M. (2010). The Promoting Effect of English Movies on College English Teaching. Movie Literature, 12, 147-148. 